\title{
Inovação social em uma cooperativa de catadores em Tangará da Serra/MT
}

As Inovações sociais são caracterizadas pelo envolvimento de stekeholders que buscam de forma conjunta soluções tecnológicas, ambientais, econômicas e sociais que criam valor para o grupo e para a sociedade. Esse trabalho buscou identificar as inovações sociais de uma Cooperativa de Catadores e teve como problema de pesquisa a investigar 'quais as dimensões e variáveis da inovação social que emergem do estudo das atividades da COOPERTAN no processo de coleta seletiva de resíduos sólidos em Tangará da Serra/MT?'. Estabeleceu como objetivos, identificar as dimensões e variáveis da inovação social na COOPERTAN. Trata-se de uma pesquisa qualitativa, com base num estudo de caso e na pesquisa-ação. Para analisar as dimensões de inovação social no contexto estudado foi utilizado o modelo de proposto por Tardif et al. (2005) e adaptado por Franzoni et al. (2016) que trabalha com base em cinco dimensões: transformações, caráter inovador, inovação, atores e processo. Os resultados mostram que na organização estudada foram identificadas as cinco dimensões de inovação social. Além disso, dada a peculiaridade do contexto estudado foram acrescentadas outras dimensões de inovação social encontradas na COOPERTAN.

Palavras-chave: Inovação Social; Cooperativa de Catadores; Estudo de Caso.

\section{Social innovation in a waste picker cooperative in Tangará da Serra/MT}

\begin{abstract}
Social innovations are characterized by the involvement of stakeholders who jointly seek technological, environmental, economic and social solutions that create value for the group and for society. This work sought to identify the social innovations of a Cooperative of Waste Pickers and had as research problem to investigate 'the dimensions and variables of social innovation that emerge from the study of COOPERTAN activities in the process of selective collection of solid waste in Tangará da Serra/MT?'. Established as objectives, identify the dimensions and variables of social innovation in COOPERTAN. It is a qualitative research, based on a case study and action research. In order to analyze the dimensions of social innovation in the studied context, the model proposed by Tardif and Harrisson (2005) and adapted by Franzoni and Silva (2016) was used based on five dimensions: transformations, innovative character, and process. The results show that in the organization studied the five dimensions of social innovation were identified. In addition, given the peculiarity of the context studied, other dimensions of social innovation found in COOPERTAN were added.
\end{abstract}

Keywords: Social Innovation; Collectors' Cooperative; Case Study.

Topic: Inovação Tecnológica

Reviewed anonymously in the process of blind peer
Received: 10/04/2018

Approved: 24/05/2018
Sandro Benedito Sguarezi (iD

Universidade do Estado de Mato Grosso, Brasil

http://lattes.cnpq.br/6517662915137218

http://orcid.org/0000-0001-7361-8977

sandrosguarezi@gmail.com

Sonia Aparecida Beato Ximenes de Melo

Universidade do Estado de Mato Grosso, Brasil

http://lattes.cnpq.br/3161014550783130

http://orcid.org/0000-0001-9142-5941

msc.soniaximenes@gmail.com

José Jaconias da Silva (id

Universidade Nove de Julho, Brasil

http://lattes.cnpq.br/1212264469092956

http://orcid.org/0000-0001-9425-2222

josejaconias@gmail.com

DOI: 10.6008/CBPC2179-6858.2018.004.0022
Anderson Gheller Froehlich (D)

Universidade do Estado de Mato Grosso, Brasil

http://lattes.cnpq.br/5073961756578407

http://orcid.org/0000-0001-6123-4706

andergf@gmail.com

\section{Referencing this:}

SGUAREZI, S. B.; MELO, S. A. B. X.; SILVA, J. J.; FROEHLICH, A. G.. Inovação social em uma cooperativa de catadores em Tangará da Serra/MT. Revista Ibero Americana de Ciências Ambientais, v.9, n.4, p.268-284, 2018. DOI: http://doi.org/10.6008/CBPC21796858.2018.004.0022 


\section{INTRODUÇÃO}

Os crescentes problemas sociais como o aumento da pobreza, das desigualdades e dos efeitos das mudanças climáticas, têm exigido da sociedade a organização para o enfrentamento desses problemas, buscando a construção de alternativas tecnológicas e sociais que possam melhorar a vida das pessoas, esse fenômeno tem sido caracterizado pelos estudiosos de inovação social (PATIAS et al., 2017). As inovações sociais são idealizadas por grupo de pessoas que se arranjam para trabalhar em conjunto na criação e implementação de novas ideias, que se tornem soluções viáveis na resolução de problemas sociais, que mitigam a capacidade das pessoas de terem melhores condições de vida (ANDRÉ et al., 2006).

Na prática as inovações sociais ocorrem numa relação de compartilhamento de informações entre os atores envolvidos, que podem ser pessoas ligadas aos mais diferentes setores como: organizações públicas, organizações não governamentais, empresas privadas que buscam soluções de problemas sociais e outros. O bom desempenho na criação das inovações sociais dependerá de como os atores envolvidos se organizam para o estabelecimento de objetivos claros e papeis de responsabilidade bem acertados entre os envolvidos, bem como da capacidade de fazer feedeback, para quando necessários realinhar objetivos e metas, pois construção de inovações sociais são complexas e muitas vezes geram conflitos (LE BER et al. 2010).

Um dos métodos mais utilizados para identificar as inovações sociais que emergem das organizações foi desenvolvido Tardif et al. (2005), que estabelece cinco dimensões de inovações sociais, sendo: transformações, caráter inovador, inovação, atores e processo. Agostini et al. (2016) identificaram que as cinco dimensões de inovação social, estão presentes em uma Organização não Governamental (ONG) ligada a saúde. Bataglin et al. (2016) avaliando as cinco dimensões da inovação social em um banco popular, constataram que os atores envolvidos tiveram ganhos tanto no processo de construção das inovações sociais como nos resultados. Ainda assim, poucos estudos avaliaram o impacto das inovações sociais nas organizações, sendo necessários mais estudos para comparar resultados e avançar no entendimento a respeito do construto inovação social e para gerar conhecimentos práticos a respeito das inovações sociais para os gestores e atores envolvidos.

Para a realização dessa pesquisa a organização estudada foi a Cooperativa de Catadores de Materiais Recicláveis de Tangará da Serra/MT (COOPERTAN). Assim estabeleceu-se como problema de pesquisa a investigar, como as dimensões e variáveis da inovação social que emergem do estudo das atividades da COOPERTAN no processo de coleta seletiva em Tangará da Serra-MT? E estabeleceu como objetivo, identificar as dimensões e variáveis da inovação social na Coperativa de Catadores COOPERTAN. Esse é um estudo de caso e para investigação das dimensões da inovação foi utilizado o modelo de Tardif e Harrisson (2005), e The Young Foundation, ambos adaptados por Franzoni et al. (2016). Esse trabalho está estrutura da seguinte forma: introdução, referencial teórico, metodologia, resultados, discussão e considerações finais. 


\section{REVISÃO TEÓRICA}

\section{Inovação social: conceitos e trajetórias}

A inovação social foi aludida pela primeira vez em 1970, em estudos de James B. Taylor e Dennis Gabor, sendo Taylor considerado pioneiro na discussão do assunto ao usar o termo para referir-se ao tipo de inovação que apresenta um novo jeito de se fazer coisas, com o intuito de causar transformação e benefício social e a satisfação de necessidades humanas, se contrapondo, principalmente, à pobreza e à criminalidade, tendo como tema central as necessidades humanas (SILVA et al., 2016). Até então o viés era puramente empresarial. A esse respeito Gutiérrez (2009) mencionam que Schumpeter foi o primeiro a destacar a necessidade de inovações sociais para garantir a efetividade econômica de uma organização, estando estas paralelas às inovações tecnológicas. Inovações que representam mudanças no capital social e humano, que levam ao aumento da produtividade e por extensão, à competitividade, ou seja, o lado social da inovação tecnológica, relacionado com a participação e gestão de talentos.

$\mathrm{Na}$ concepção schumpeteriana, a ideia de inovação esteve por um longo período quase exclusivamente ligada ao domínio tecnológico, impulsionando o lucro e o ganho econômico. No entanto, com a persistência e o aumento de problemas da humanidade como a pobreza, os efeitos das mudanças climáticas e os chamados "problemas perversos", considerados complexos, surgiram novas perspectivas interdisciplinares e multiformes sobre essa temática, e a noção de inovação social tem ganhado cada vez mais importância nas esferas culturais, sociais, políticas, econômicas e psicológicas (PATIAS et al., 2017).

A partir daí o termo inovação social difunde-se com mais ênfase entre pesquisadores e cientistas. Para Bignetti (2011), inovação social é definida como o resultado do conhecimento aplicado a necessidades sociais através da participação e da cooperação dos atores envolvidos, gerando soluções novas e duradouras para grupos sociais, comunidades ou para a sociedade em geral. Na visão de alguns autores como Taylor (1970), Cloutier (2003), Novy et al. (2005), André et al. (2006), Moulaert et al. (2007), Murray (2010), Delgado (2016) inovação social trata-se de processos, idealizados por stakeholders sociais, que se organizam para criar novas ideias, responder ao desejo, à necessidade, encontrar solução, a promoção de mudanças nas relações sociais e culturais. Bem como, a geração de capacitação que impacta na resolução de problemas sociais, e a criação de novas oportunidades que beneficie a sociedade, melhora a qualidade e as condições de vida na comunidade.

Ainda sobre o conceito de inovação social Phillips et al. (2015) a definem como sendo uma solução nova e útil para um problema social, respondendo de forma mais eficaz, eficiente e sustentável que as abordagens de inovação já existentes, favorecendo toda a sociedade com a criação de valor, ou seja, com ganhos coletivos em vez de privados, que reduzem as desigualdades sociais. Como exemplo de inovação social, os autores citam microfinanças e comércio justo. Para Le Ber et al. (2010), os objetivos finais da inovação social incluem resumidamente a justiça, a preservação ambiental, a melhoria da saúde, artes e cultura e uma educação melhor. 
Nessa perspectiva, a geração de inovação social, segundo André et al. (2006) deve simultaneamente atender a três requisitos: i) satisfação das necessidades humanas, não atendidas pelas vias convencionais, ou seja, o mercado; ii) como resultado, a promoção da inclusão social; e iii) a capacitação de atores sociais sujeitos, potencial ou efetivamente, a risco de exclusão/marginalização social, proporcionando uma mudança mais ou menos intensa das relações de poder.

Nesse caso, as estruturas sociais precisam ser alteradas profundamente para que a inovação social) tenha os efeitos esperados. Moore et al. (2011) coaduna com essa percepção. O autor entende que a inovação social somente será bem-sucedida quando provocar grande impacto social e for duradoura, ou seja, um efeito perturbador sobre o sistema social e as instituições sociais que regem a conduta, afetando, de forma fundamental, a distribuição de poder e recursos, as crenças básicas que definem o sistema, ou as leis e as rotinas que o direcionam.

As tecnologias sociais são a grande propulsora das inovações sociais. Elas têm a finalidade de desenvolvimento social acessível à coletividade, cujos objetivos consistem em promover a inclusão social, mobilizar territórios, apresentar alternativas nas mais diversas áreas e solucionar problemas sociais, econômicos e ambientais (OLIVEIRA et al., 2012).

Assim sendo, a melhoria efetiva das condições de vida constitui-se em um dos principais objetivos do desenvolvimento de tecnologias sociais. Por essa razão, pode-se afirmar que as práticas que envolvem tecnologia social encontram-se em sintonia com a definição de inovação social que, segundo André et al. (2006), Phillips et al. (2015), refere-se a atividades e serviços inovadores, que visam e geram mudança social, que se difundem predominantemente entre as organizações que têm como primeiro propósito o desenvolvimento social.

A partir daí a ligação entre tecnologia social, inovação social e empreendedorismo coletivo se estabelece de forma natural e harmoniosa, visto que a proposta comum está centrada na ideia de transformação social. Essa tríade se alicerça no conceito universalmente aceito de desenvolvimento sustentável. A formação de empreendimentos coletivos por pessoas que buscam a integração social e a inserção produtiva compreende um ambiente propicio à geração de inovações sociais sustentáveis. Fica evidente que as inovações sociais podem ser mais facilmente difundidas em organizações cujos interesses transcendem o lucro e o ganho econômico per si. Mas existem diversas formas de organização em que as inovações sociais se tornam um campo fértil para o desenvolvimento social.

\section{A inovação social e suas formas de organização}

Farfus et al. (2007) assevera que inovação social compreende a busca, descoberta, experimentação, desenvolvimento, imitação e adoção de 'arranjos sociais alternativos' para produzir algo. E define os arranjos sociais alternativos como sendo outras formas de organizar o esforço coletivo de produção, diferenciando das formas tradicionais de produção. Portanto, formas diferentes daquelas normalmente adotadas pelas empresas estritamente econômicas, cujo objetivo de constituição está focado no lucro e na competitividade. 
Para Phillips et al. (2014), a inovação social ocorre em várias formas de organização, de empresas com fins lucrativos que muitas vezes criam valor social através de seus programas de Responsabilidade Social Empresarial, para organizações de modelos híbridos. Para o autor, os empreendedores sociais adotam uma abordagem comercial ou se concentram em melhorar os resultados sociais de uma determinada comunidade ou grupo de partes interessadas.

Por sua vez, André et al. (2006) e Quirino et al. (2015) entendem que a inovação social é representada principalmente por instituições do terceiro setor, mas também pode ser atualizada em políticas públicas instituídas pelo governo e medidas de responsabilidade social adotadas por empresas privadas. Nesse caso, as empresas do terceiro setor podem estabelecer parcerias para construção de inovações sociais. O sucesso ou fracasso dessas parcerias vai depender de como essas empresas estabelecem seus objetivos e papeis na construção das inovações e como elas se comunicam.

Quanto mais precisos os objetivos estabelecidos e mais claros os papeis de cada empresa melhor será a capacidade de gerar inovações sociais, além disso, é necessário durante o processo de geração das inovações, recalibrar os objetivos e metas, a fim de obter mais sucesso como geradora de inovações sociais (LE BER et al., 2010).

Os empreendedores sociais existem dentro de um sistema de inovação social, uma comunidade de profissionais e instituições abordando conjuntamente questões sociais, ajudando a moldar a sociedade e as inovações. Os sistemas de inovações sociais podem ser vistos como um conjunto de subsistemas interrelacionados que podem agir de forma independente, mas, por meio de aprendizagem interativa e coletiva, contribuindo para abordar necessidades e preocupações sociais (PHILLIPS et al., 2015). Os autores ainda argumentam que as inovações sociais podem atravessar fronteiras e setores e podem exigir o acesso a uma variedade de recursos e competências que se situam além de ambientes imediatos de uma organização. Portanto, o aprendizado interativo e coletivo desempenha um papel intrínseco na construção das inovações sociais.

Por fim, Oliveira et al. (2012), realçam que o cooperativismo, por empregar valores e princípios como ajuda mútua, solidariedade e gestão participativa, pode proporcionar o desenvolvimento de ações valiosas de tecnologias sociais no âmbito dos empreendimentos coletivos, os quais promovem a inclusão social, mobilizam territórios, apresentam alternativas nas mais diversas áreas e solucionam problemas de natureza social e econômica. Independente da forma organizacional, importante que esteja engajada em um modelo de inovação social capaz de atender às necessidades e objetivos propostos.

\section{Modelo para inovação social e sua aplicabilidade}

De acordo com Franzoni et al. (2016) diversos autores propuseram modelos e escalas com o objetivo de analisar as inovações sociais. Um desses modelos Tardif et al. (2005), analisaram uma base contendo 49 estudos realizados pelos pesquisadores do Crises acerca do tema, e chegaram a cinco dimensões de análise: Transformações, Caráter Inovador, Inovação, Atores e Processo. A Quadro 1 resume sua abrangência. 
Quadro 1: Modelo de dimensões de análise de inovações sociais.

\begin{tabular}{|c|c|c|}
\hline \multicolumn{2}{|l|}{ Dimensões } & Descrição/Elementos \\
\hline \multirow[t]{3}{*}{ Transformações } & $\begin{array}{l}\text { Contexto macro/ } \\
\text { micro }\end{array}$ & Crises, rupturas, descontinuidades, mudanças estruturais; \\
\hline & Econômica & Emergência, adaptação, relações de trabalho/ produção/ consumo; \\
\hline & Social & $\begin{array}{l}\text { Recomposição, reconstrução, exclusão/marginalização, prática, mudança, } \\
\text { relações sociais. }\end{array}$ \\
\hline \multirow[t]{3}{*}{ Caráter inovador } & Modelos & De trabalho, de desenvolvimento, de governança, de Quebec; \\
\hline & Economia & Do saber, do conhecimento, mista, social; \\
\hline & Ação social & $\begin{array}{l}\text { Tentativas, experimentos, políticas, programas, arranjos institucionais, } \\
\text { regulamentação social. }\end{array}$ \\
\hline \multirow[t]{3}{*}{ Inovação } & Escala & Local \\
\hline & Tipos & Técnica, sociotécnica, social, organizacional, institucional; \\
\hline & Finalidade & Bem comum, interesse geral, interesse público, cooperação \\
\hline \multirow[t]{4}{*}{ Atores } & Sociais & $\begin{array}{l}\text { Movimentos cooperativos/ comunitários/voluntários, sociedade civil, } \\
\text { sindicatos; }\end{array}$ \\
\hline & Organizações & $\begin{array}{l}\text { Empresas, organizações de economia social, empreendimentos coletivos, } \\
\text { beneficiários; }\end{array}$ \\
\hline & Instituiç̧̃̃es & Estado, identidade, valores/normas; \\
\hline & Intermediários & Comitês, cadeias curtas sociais/de alianças/de inovação. \\
\hline \multirow[t]{3}{*}{$\begin{array}{l}\text { Processos e atividades } \\
\text { coletivas }\end{array}$} & $\begin{array}{l}\text { Modo } \\
\text { coordenação }\end{array}$ & Avaliação, participação, mobilização, aprendizagem; \\
\hline & Meios & Parcerias, consultas, integração, negociação, empoderamento, difusão; \\
\hline & Restrições & $\begin{array}{l}\text { Complexidade, incerteza, resistência, tensão, compromisso, rigidez } \\
\text { institucional. }\end{array}$ \\
\hline
\end{tabular}

Fonte: Tardif et al. (2005).

Agostini et al. (2016) destacam que as dimensões propostas por Tardif et al. (2005) da inovação social são: modificar ou transformar uma necessidade social; apresentar solução inovadora; implementação da inovação social; envolvimento dos atores e partes interessadas; e resultados efetivos. Desse modo, os autores argumentam que a diversidade de atores e a participação ativa do indivíduo é fundamental no papel do processo da inovação social. Nesse sentido, as necessidades sociais devem ser vistas como uma oportunidade para encontrar respostas para múltiplas crises sociais, econômicas e ambientais. As transformações são os resultados obtidos pela inovação social, no sentido de soluções e respostas, pela profundidade das mudanças causadas no ambiente.

De acordo com Franzoni et al. (2016) no modelo sugerido por The Young Foundation, existem sete estágios para o desenvolvimento da inovação social (Figura 1), que podem ser pensados como espaços de sobreposição, com culturas e habilidades distintas e fornecem uma estrutura para a reflexão sobre os diferentes tipos de apoio que os inovadores e inovações precisam para crescer.

No estudo de Santos et al. (2016) foi possível verificar a aplicabilidade das dimensões de inovações sociais propostas por Tardif et al. (2005) em uma cooperativa. Identificando as ações de inovação social presentes desde a implantação do projeto e que estas ações têm alcançado relevância social e econômica na vida das pessoas envolvidas no processo.

O estudo João (2014) que objetivou identificar quais as práticas que interferiram positivamente no processo de inovação social das empresas sociais, e que deveriam ser difundidas visando aumentar a geração da inovação social. Os resultados apontaram que a inovação social ocorreu tanto de forma planejada como ocasional, e que o diálogo entre a equipe de trabalho; a participação em redes específicas de inovação social; brainstorming; benchmarking; equipe multidisciplinar altamente motivada; novos enquadramentos para os 
problemas sociais; estrutura organizacional horizontalizada e envolvimento da comunidade são práticas eficientes e eficazes na geração da inovação social.

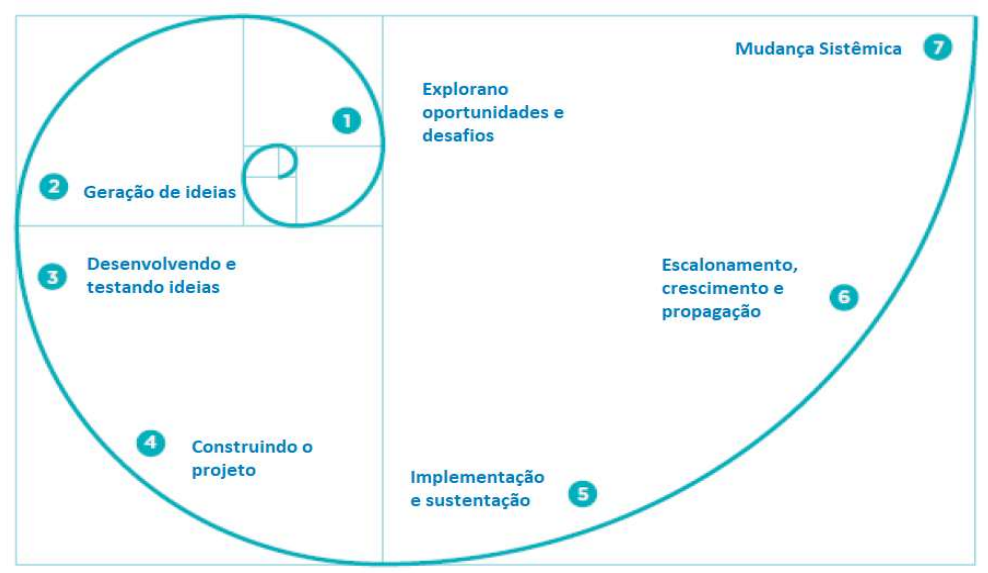

Figura 1: Diferentes estágios da inovação social. Fonte: Franzoni et al. (2016).

Por fim, Franzoni et al. (2016) ao analisaram as perspectivas da inovação social, tecnologia social e cadeias agroalimentares curtas da cadeia de agricultores familiares fornecedora da alimentação escolar da cidade de Porto Alegre e evidenciaram que todas as dimensões de inovação social estavam presentes no objeto estudado, assim como parte dos seus elementos. Como uma inovação social, no contexto estudado, ela encontra-se no estágio de execução e sustentação.

\section{METODOLOGIA}

Essa pesquisa se caracteriza como um estudo de caso, "os estudos de caso vem sendo cada vez mais reconhecidos como delineamento capaz de proporcionar resultados significativos nas pesquisas no campo da administração" (GIL, 2005). O caso a ser analisado são as inovações sociais da Cooperativa de Catadores de Tangará da Serra/MT - COOPERTAN.

Os dados foram levantados na COOPERTAN por meio da pesquisa-ação e da observação participante no ano de 2017. A pesquisa-ação está associada a diversas formas de ação coletiva e dirigida para pesquisas que buscam resolver problemas, que visam uma transformação social. A solução dos problemas na pesquisaação segue cinco etapas básicas: começa com a identificação do problema, o planejamento de uma solução, sua implementação, seu monitoramento e a avaliação de sua eficácia (TRIPP, 2005).

A observação participante é uma técnica cada vez mais utilizada na administração por permitir observar um fenômeno e suas interações diretamente. "A técnica de observação vem sendo utilizada em diversas áreas de conhecimento, visto que a mesma possibilita ao pesquisador extrair informações de grupos e situações que com outras técnicas se tornariam mais complexo ou mesmo impossíveis" (FERREIRA et al., 2012).

As observações foram feitas buscando entender como as inovações sociais estão inseridas na COOPERTAN, no modelo proposto por Tardiff et al. (2005) (Quadro 1) pelas cinco dimensões transformações, caráter inovador, inovação, atores e processo. E os estágios da inovação social pelo modelo proposto por The Young Foundation ambos adaptados de Franzoni et al. (2016). 


\section{RESULTADOS}

$\mathrm{Na}$ análise da cadeia produtiva da reciclagem da COOPERTAN foram encontradas praticamente todas as dimensões de inovação social, com parte dos seus elementos presentes no contexto de criação de cooperativas, sua trajetória e desenvolvimento e seu diálogo com a inclusão socioprodutiva de catadores através da prática da coleta seletiva. Encontramos pelo menos três inovações sociais no contexto de criação da COOPERTAN. Se a Inovação Social visa mitigar ou resolver um problema social, no contexto local, a criação da COOPERTAN, por si só, representa uma Inovação Social. Outra Inovação Social que pode ser apontada é a iniciativa coletiva de Catadores e Catadoras de materiais recicláveis construir um processo de autogestão dentro desse empreendimento. A terceira inovação social trata da organização da sociedade e do poder público local para a implantação da coleta seletiva através do Programa Tangará Recicla.

\section{Dimensão transformações}

No que se refere a dimensão 'Transformações' elencou-se os seguintes elementos caracterizados na COOPERTAN. O surgimento da inovação social ocorreu num contexto macro e micro acompanhado de: Crises (tanto econômica quanto sociais), rupturas de relações de trabalho e de produção, descontinuidades (saída do lixão e criação da cooperativa, mudanças estruturais, as relações de produção mudaram as relações de trabalho que exigiram a qualificação para a autogestão da cooperativa e transformações sociais. Foi observado outro elemento que pode ser acrescentado ao quadro de análise na dimensão Transformações. É o elemento ambiental: educação ambiental; conscientização ambiental; eficiência e sustentabilidade.

\section{Dimensão caráter inovador}

Quando se trata da dimensão 'Caráter Inovador', a COOPERTAN comporta alguns elementos. A descrição referente aos seus modelos (de trabalho e de governança). Os tipos de economia que a cooperativa a presenta é o misto e social. O primeiro pelas características de trabalho coletivo e solidário, pela organização do trabalho associado e da autogestão que mostra autonomia desses trabalhadores. $O$ segundo em ações em redes de colaboração solidária com outras organizações que atendem interesses de diferentes empreendimentos num processo de desenvolvimento local sustentável. Percebeu-se a ação social geradora da inovação social (interação da política nacional de resíduos sólidos com a política municipal de economia solidária). Também foi identificado o modelo de Quebec, devido ao processo de autogestão que comporta uma organização coletiva própria do trabalho associado, em redes de colaboração solidária que comportam a governança participativa e visam a construção e a consolidação de políticas públicas.

\section{Dimensão inovação}

Tratando-se da dimensão 'Inovação', que abarca a escala, tipo e finalidade (desenvolvimento local) das inovações sociais, o contexto da COOPERTAN demonstra e concentra em poucos elementos. A escala de 
atuação da inovação social, pela abrangência da COOPERTAN, é local com impacto regional. O tipo de inovação institucional e social.

\section{Dimensão atores}

Quando a análise recai sobre a dimensão Atores, o processo de inovação social na COOPERTAN identificou os quatro elementos nessa dimensão: Elementos sociais com formação de redes sociais de cooperação e inovação; organizações (Impacto no desenvolvimento de outras comunidades e outros empreendimentos); instituição (articulação em programas e projetos com o município); intermediários (como a Universidade, programas e projetos, Conselhos, Comissões gestoras). Atores sociais e institucionais, estão presentes nas diferentes articulações da cooperativa estudada e foram os que mais apareceram nessa análise.

\section{Dimensão processo}

A análise da dimensão 'Processo' é composta pelo modo de coordenação das inovações sociais e evidencia os meios e as restrições encontradas no modelo sugerido por The Young Foundation (2014), que apresenta os sete estágios para o desenvolvimento da inovação social. Os processos de coordenação evidenciados a partir do modelo sugerido foram: avaliação, participação, mobilização e aprendizagem. Também foi identificado os meios (parcerias públicas e privadas) e na restrição apresentam complexidade no gerenciamento da autogestão, incerteza, resistência, rigidez institucional.

Esses modos e processos de coordenação aparecem na cadeia da reciclagem da COOPERTAN também na maioria das organizações. Os meios identificados para produzir esses processos na organização estudada se revelaram externamente através da forte parceria com outras entidades, sejam do Estado, da sociedade civil ou do mercado. E internamente pela solidariedade, cooperação e integração entre os seus sócios/beneficiários e pela autonomia e empoderamento de seus associados.

No que se refere às restrições do processo foram encontrados a complexidade no gerenciamento da autogestão, em gerenciar a participação das pessoas no processo de tomada de decisão e junto aos cooperados devido ao conflito de interesses e necessidades diferentes, conflito entre o paradigma capital versus trabalho (nem sempre os cooperados se sentem donos da cooperativa), isso causa falta de comprometimento de alguns desses atores. A incerteza foi outro aspecto encontrado frente aos desafios sucesso/fracasso da iniciativa de criar o próprio empreendimento. Também apareceu a resistência de alguns membros ao trabalho associado, originada em experiências coletivas não exitosas. Como restrição a tensão outro ponto encontrado foi a inserção de novos cooperados na organização, isso decorre porque a maioria dos trabalhadores desconhece os princípios e os valores do trabalho coletivo, ou seja, ainda estão presos ao paradigma do emprego.

Outro ponto importante que apareceu como uma das principais dificuldades foi a rigidez institucional, a burocracia dos órgãos públicos no processo de interação com a COOPERTAN no processo de implantação da coleta seletiva bem como na gestão do processo. 
Integração das dimensões

Das cinco dimensões de inovação social analisadas na COOPERTAN, todas foram identificadas conforme sumarizado na Quadro 2.

Quadro 2: As dimensões de inovações sociais na COOPERTAN.

\begin{tabular}{|c|c|c|}
\hline \multicolumn{2}{|l|}{ Dimensões } & Descrição/Elementos \\
\hline \multirow{4}{*}{ Transformações } & $\begin{array}{l}\text { Contexto macro/ } \\
\text { micro }\end{array}$ & Crises, rupturas, descontinuidades, mudanças estruturais; \\
\hline & Econômica & Emergência, adaptação, relações de trabalho/ produção/ consumo; \\
\hline & Social & $\begin{array}{l}\text { Recomposição, reconstrução, exclusão/marginalização, prática, mudança, } \\
\text { relações sociais. }\end{array}$ \\
\hline & Ambiental & Educação ambiental, conscientização ambiental, eficiência, sustentabilidade \\
\hline \multirow{3}{*}{ Caráter inovador } & Modelos & De trabalho, de desenvolvimento, de governança, de Quebec; \\
\hline & Economia & Do saber, do conhecimento, mista, social; \\
\hline & Ação social & $\begin{array}{l}\text { Tentativas, experimentos, políticas, programas, arranjos institucionais, } \\
\text { regulamentação social. }\end{array}$ \\
\hline \multirow{3}{*}{ Inovação } & Escala & Local, Regional \\
\hline & Tipos & Técnica, sociotécnica, social, organizacional, institucional; \\
\hline & Finalidade & Bem comum, interesse geral, interesse público, cooperação \\
\hline \multirow{4}{*}{ Atores } & Sociais & $\begin{array}{l}\text { Movimentos cooperativos/ comunitários/voluntários, sociedade civil, } \\
\text { sindicatos; }\end{array}$ \\
\hline & Organizações & $\begin{array}{l}\text { Empresas, organizações de economia social, empreendimentos coletivos, } \\
\text { beneficiários; }\end{array}$ \\
\hline & Instituições & Estado, identidade, valores/normas; \\
\hline & Intermediários & $\begin{array}{l}\text { Comitês, Conselhos, Comissões gestoras, cadeias curtas sociais/de } \\
\text { alianças/de inovação. }\end{array}$ \\
\hline \multirow{3}{*}{$\begin{array}{l}\text { Processos e atividades } \\
\text { coletivas }\end{array}$} & $\begin{array}{l}\text { Modo de } \\
\text { coordenação }\end{array}$ & Avaliação, participação, mobilização, aprendizagem; \\
\hline & Meios & $\begin{array}{l}\text { Parcerias, consultas, integração, negociação, articulação, solidariedade, } \\
\text { autonomia, empoderamento, difusão; }\end{array}$ \\
\hline & Restrições & $\begin{array}{l}\text { Complexidade, incerteza, resistência, conflito, tensão, compromisso, rigidez } \\
\text { institucional. }\end{array}$ \\
\hline
\end{tabular}

Fonte: Adaptado de Franzoni et al. (2016).

A consolidação da exploração da cadeia produtiva da reciclagem no município, nesse caso, passa pela criação da COOPERTAN que opera o Programa Tangará Recicla desenvolvendo a atividade da coleta seletiva de materiais recicláveis no município de Tangará da Serra/MT. Dessa forma, acredita-se que o processo de inovação social na COOPERTAN que faz parte da cadeia produtiva dos materiais recicláveis propiciou várias conquistas para seus principais beneficiários, também ocorrendo a difusão dos seus benefícios para outros contextos. À partir daqui passamos a análise dos diferentes estágios da inovação social propostos conforme Figura 1.

Explorando oportunidades e desafios: a inovação social, nesse contexto bastante complexo surgiu quando os catadores foram obrigados a organizar a cooperativa, visto que não poderiam mais desenvolver sua atividade dentro do Aterro Sanitário que passava pelo processo de licença operacional pelos órgãos competentes e, em um momento subsequente, no processo de implantação da coleta seletiva porta-a-porta na cidade;

Geração de ideias: fase em que a cooperativa se organiza. É o momento da criação da cooperativa, a fase da transição do trabalho individual para o trabalho associado, é o momento em que o conceito de autogestão passa pela práxis dos trabalhadores sócios da cooperativa. É o desafio de enfrentar um novo paradigma de trabalho e superar a relação de emprego. Esse momento a COOPERTAN contou com o auxílio 
da universidade via incubadora, da prefeitura-poder público local via Núcleo de Participação Social de Economia Solidária (NUPES).

Desenvolvendo e testando ideias: fase em que os catadores associados da COOPERTAN desenvolvem iniciativas para superar os próprios problemas, buscam a formação técnica via processos de incubação, dialogar e negociar com o poder público local para a ampliação da coleta seletiva para garantir a sua consolidação. Nesse estágio são elaborados o regimento interno da cooperativa, ações de formação em cooperativismo e reciclagem e outras estratégias de experimentação no sentido de melhorar a articulação da cadeia produtiva da reciclagem;

Construindo o projeto: fase de consolidação, é quando a COOPERTAN se torna referência, apresenta e aprova projetos junto à financiadores externos, recebe o apoio de outras instituições, e o reconhecimento da sociedade. É o momento em que os catadores passam a assumir de fato e de direito sua organização, desenvolvem identidade e se amplia o engajamento efetivo dos seus integrantes. Também recebe o apoio institucional, principalmente da incubadora da UNEMAT que pela metodologia da pesquisa-ação elabora o plano de negócios, plano de ação e projetos que visam captar recursos para fomentar as ações da cooperativa;

Instituição e sustentação: fase em que se consolida a coleta seletiva de materiais recicláveis via cooperativa. Assim a COOPERTAN tornou-se ator importante da cadeia da reciclagem e na vida de seus beneficiários. É nesse momento que prática do trabalho associado se torna uma realidade cotidiana para deles. É o momento que os associados internalizam os valores da cooperação e da solidariedade.

Escalonamento, crescimento e propagação: esse item também foi encontrado na análise da COOPERTAN. Após dez anos de fundação (12 de julho de 2017), o estágio de difusão das inovações sociais da COOPERTAN se dão no próprio contexto, pelo domínio das técnicas e metodologia da coleta seletiva portaa-porta; pela internalização dos valores da autogestão e pelo reconhecimento institucional e social que a COOPERTAN adquiriu.

Mudança sistêmica: Ocorre na cooperativa estudada, quando esta leva a difusão das inovações sociais se dão na COOPERTAN para a Rede Catamato, que desde o início da sua criação assume o compromisso os princípios e a práxis da autogestão. Também ocorre quando a COOPERTAN colabora na construção do projeto de coleta seletiva porta-a-porta junto a Cooperativa Chapadense de Materiais Recicláveis (COOPCHAMAR) em Chapada dos Guimarães. E posteriormente leva sua experiência para um grupo de catadores oriundos do 'Lixão' de Cáceres MT visando a organização de uma associação e a implantação da seletiva porta-a-porta naquela cidade. Isto posto, constatou-se aumentando sua abrangência e mudança sistêmica para outros contextos.

Dessa forma, acredita-se que o processo de inovação social na COOPERTAN que faz parte da cadeia produtiva dos materiais recicláveis propiciou várias conquistas para seus principais beneficiários, também ocorrendo a difusão dos seus benefícios para outros contextos. 


\section{DISCUSSÃO}

Todo processo de criação de inovação social está envolto numa realidade complexa que exige dos diferentes atores sociais capacidades dialógicas para responder às demandas sociais através paradigmas diferentes daqueles que criaram o problema. Ou seja, é fundamental pensar uma resposta interdisciplinar para o problema que se quer resolver. Também é importante considerar o contexto cultural, social, político, econômico, ambiental, a qualificação das pessoas, o nível de tecnologia e recursos financeiros disponível dentre outros. Nesse cenário a pergunta problema é: quais as dimensões e variáveis da inovação social que emergem do estudo das atividades da COOPERTAN no processo de coleta seletiva em Tangará da Serra/MT?

Neste contexto, Moraes (2004) define inovação como "uma forma mais especializada de mudança. Todas as inovações envolvem mudanças, mas nem todas as mudanças, necessariamente, envolvem novas ideias ou conduzem a melhorias significativas. Para Magalhães (2007) inovação é "toda mudança evolutiva ou disruptiva, em qualquer das dimensões competitivas, que tiver como objetivo prolongar a vida das organizações". As inovações encontradas neste estudo dizem respeito à as propostas por Tardif et al. (2005). A Dimensão Transformações trata do contexto em torno das mudanças, com ênfase sobre os conceitos de crise, ruptura e descontinuidade, em ambas as escalas, macro e micro transformação social (ALTER, 2000; CALLON et al., 2001), percebe-se na prática investigada, que, de fato, a inovação social tem evidenciado tal transformação.

Do ponto de vista Macro, da dimensão transformação o processo de globalização que promoveu à partir dos anos de 1990 um aprofundamento das diferenças sociais, concentração de riqueza, desemprego, miserabilidade aumento dos problemas ambientais, dentre eles a grande produção de lixo, hoje materiais recicláveis). Do ponto de vista micro o processo de criação da cooperativa seu deu num momento crítico tanto para o poder público local representado pela autarquia Serviço Autônomo de Água e Esgoto (SAMAE), para os Catadores e para a sociedade.

Para o poder público a necessidade da instalação do Aterro Municipal era urgente, porém com os Catadores trabalhando no aterro a Secretaria Estadual de Meio Ambiente (SEMA) não emitiria licença de operação. Para os catadores o ponto crítico era criar uma forma de organização que lhes garantisse as condições de trabalho, que apesar de insalubres era o que Ihes garantia a sobrevivência. Além disso, o resultado do trabalho era comercializado individualmente e direto como atravessador, ou seja, os catadores não tinham o mínimo de poder de barganha ou de escala de produção, essa emergência econômica que originou a criação da cooperativa. O problema ambiental emergente da produção de lixo/material reciclável advém do consumo, é uma dificuldade da sociedade que também pesou nessa decisão. A solução desses problemas seu deu pelo surgimento da cooperativa, visto que com a criação da COOPERTAN os trabalhadores passam a ter um espaço de trabalho mais digno e fora do Aterro Sanitário. Os trabalhadores também passam a conviver com novas relações de trabalho e de produção, que antes se davam na base da competitividade e agora se dão com base na solidariedade e da cooperação. Com a criação da Cooperativa resolveu outro problema que era o entrave para a emissão da licença de operação. Consequentemente permitiu a 
implantação da coleta seletiva através do Programa Tangará Recicla que resolveu um problema da sociedade: o descarte correto dos materiais recicláveis.

Por sua vez, a questão econômica possibilitou a emergência e acesso a remuneração mais adequada. A organização da cooperativa permitiu que os trabalhadores obtivessem melhor remuneração pelos seus produtos. A ampliação da escala de produção permitiu a venda de materiais recicláveis em volumes maiores (cargas fechadas), isso elevou a remuneração pelo trabalho. Todo esse processo exigiu a adaptação desses trabalhadores que passam a utilizar máquinas, ferramentas e equipamentos que diminuem o esforço e a fadiga e aumentam a produção. Ainda no que se refere à produção, com a implantação da coleta seletiva houve uma transformação radial do processo produtivo. Antes os trabalhadores catavam no 'lixão', no Aterro Sanitário. Agora recebem o material por meio da coleta seletiva.

O processo de autogestão se caracteriza por uma inovação social porque esses trabalhadores precisaram superar a lógica de mercado da exploração do trabalho, vincada no emprego e construir outras relações de produção e de trabalho baseadas no trabalho associado e na lógica da solidariedade. É preciso cambiar o paradigma do emprego que pressupõe uma relação subordinada e hierarquizada para o paradigma da autogestão que pressupõe a organização do trabalho numa linha horizontal na qual não existe patrão nem empregado, e sim sócio da cooperativa e estabelecer-se no mercado que contraditoriamente comporta uma lógica de competição. Expõe Phills et al. (2008) que o desenvolvimento de atividades voltadas à inovação social se estabelece na criação de benefícios com resultados que vão além dos ganhos privados aos benefícios proporcionados pelo mercado.

Do ponto de vista social esse conjunto de transformações permitiram a recomposição e a reconstrução do tecido social gerando novos postos de trabalho que iniciou com a cooperativa de 20 sócios e atualmente é composta de 47 sócios, um acréscimo de 135\%, garantiu a inclusão minimizando a exclusão/marginalização retirando os catadores da marginalidade social, da invisibilidade. Também garantiu o resgate da dignidade e da autoestima desses trabalhadores. Essa mudança, exigiu a qualificação para os catadores no sentido de melhorar a qualidade da produção e mesmo a convivência dentro do grupo. Alterou os padrões de produção, passando do trabalho individual para o coletivo. Do ponto de vista do consumo ampliou a renda das famílias e permitiu maior acesso a bens de consumo de primeira necessidade, ainda que esse consumo se efetive nos moldes e na lógica do mercado hegemônico. Nesse sentido, Klein et al. (2009) argumenta que a inovação social tanto altera como reestrutura o ambiente institucional da comunidade e conduz à transformação social. Assim, percebe-se que as ações praticadas pela COOPERTAN corroboram com o argumento de Bernard et al. (2017) que a inovação social pode ser uma solução eficaz, eficiente e sustentável para um problema social, e as soluções existentes se estendem à sociedade como um todo e não apenas a indivíduos de forma particular.

Autores como Barbieri et al. (2009), Maçaneiro et al. (2010), têm debatido a respeito de uma gestão da inovação que considere a questão da sustentabilidade. Estes autores expressam que a inovação é essencial para a sustentabilidade dos empreendimentos tanto nas dimensões ecológica, como social, econômica e cultural sem priorizar uma delas em detrimento das demais. Nesse contexto a COOPERTAN 
desenvolve ações de educação ambiental junto às escolas, faculdades, universidades e outros públicos junto à comunidade. Esse processo leva a eficiência ambiental e melhora significativamente a qualidade dos materiais recicláveis que serão destinados à cooperativa, e diminuiu a quantidade de materiais que poderiam ser destinados ao Aterro Sanitário. A perspectiva ambiental decorre do potencial da atividade de reciclagem de diminuir o impacto da poluição gerada pelos resíduos sólidos no meio ambiente ampliando a vida dos aterros sanitários. Portanto, se existe uma atividade que realmente dialoga com o conceito de sustentabilidade é a coleta seletiva de matérias recicláveis, visto que é uma atividade economicamente viável, socialmente justa e ecologicamente correta.

No contexto do caráter sistêmico cujo sucesso depende da externalidade e de produtos e serviços externos (TIDD et al. 2015), a COOPERTAN integra modelos de governança da cadeia produtiva da reciclagem que interagem com a política municipal de Economia Solidária, e especialmente da política de gestão de resíduos sólidos através do Programa Tangará Recicla. É notável o modelo de trabalho em rede junto a outras organizações mais autônomas como é o caso da Rede Autogestionária de Cooperativas e Associações de Catadores de Resíduos Sólidos do Estado de Mato Grosso (REDE CATAMATO), criada em 2012 e composta por três Empreendimentos Econômicos Solidários (EES). Também é o caso da Rede Fundo Rotativo Solidário Unidos Vivendo em Ação (Rede FRS-UVA) composta pela COOPERTAN e outros cinco EES.

Nesse quesito Rufino (2005) aborda em seu estudo que os indivíduos inseridos em organizações autogestionárias tendem a aprimorar suas atividades organizacionais, pois ao discutirem em grupo suas necessidades passam a gerar soluções criativas tanto produtiva quanto financeiras. Ações sociais geradoras do processo de inovação social passam por tentativas (erros e acertos) e desenvolvimento de experiências de arranjos institucionais com base na Política Nacional de Resíduos Sólidos (PNRS 2010), é o caso do Programa Fortalecimento da Infraestrutura de Cooperativas de Catadores para Coleta, Transporte e Comercialização de Materiais Recicláveis - Logística Solidária Cataforte e o Projeto: Ação de Fomento a Empreendimentos Econômicos Solidários e Redes de Cooperação Constituídas por Catadores e Catadoras de Materiais Reutilizáveis e Recicláveis (Projeto: Pró-Catador), tudo com o objetivo de viabilizar o surgimento e a consolidação de organizações de catadores apoiadas por programas e políticas públicas.

A escala de atuação da inovação social, quando se avalia o protagonismo da COOPERTAN na criação da Rede Catamato, na articulação de políticas públicas estaduais se percebe uma abrangência regional. 0 impacto institucional da ação da cooperativa estudada na criação da política municipal da coleta seletiva, caracteriza que o tipo de inovação social institucional. Assim como o tipo social, que se caracteriza pelo apoio à criação de novos empreendimentos como é o caso da Rede FRS-UVA e da Rede Catamato. A inovação organizacional ocorreu na COOPERTAN pela inovação social da autogestão. Também foi perceptível a adequações técnicas e sócio técnicas principalmente nos processos de gestão. Essas inovações sociais sempre buscavam por meio dos princípios da Economia Solidária e processos de cooperação a consolidação da COOPERTAN e de empreendimentos ligados a ela por redes de colaboração solidária que tem por interesse o bem comum, a sociedade e o desenvolvimento local sustentável. 
A dimensão 'Atores sociais' da COOPERTAN apresenta forte articulação sociedade civil e economia solidaria, a sociedade cível por meios do Movimento Nacionais de Catadores de Recicláveis (MNCR) e o do Movimento da Economia Solidária. Impacto no desenvolvimento de outras comunidades e outros empreendimentos; com outras organizações da economia solidária, empresas que fazem parte da cadeia produtiva da reciclagem, e os trabalhadores beneficiários, no caso os Catadores.

Ao contrário do que ocorre com inovações técnicas, que se pode ver melhoria tangível, as inovações sociais são, por vezes, difíceis de serem identificadas. Isso ocorre porque a inovação social é uma mudança de atitudes, comportamentos e percepções, que resultam em uma nova forma de ação colaborativa e que levam à melhoria da qualidade de vida (NEUMEIER, 2012).

O elemento 'intermediário' da dimensão atores mostrou a participação da COOPERTAN na Comissão Gestora do Pró-Catador, representação no Conselho Municipal de Economia Solidária no sentido de consolidar alianças para garantir a perenidade do empreendimento e por consequência da inovação social por ele produzida. O elemento institucional aparece na relação com o Estado, nas três esferas, nas negociações e articulações por projetos, programas e políticas públicas voltadas para os catadores, o que revela uma forte identidade desse coletivo que pauta suas ações por normas e valores da Economia Solidária.

Os primeiros devido ao compromisso com o Movimento da Economia Solidária e processos colaborativos em redes e sua articulação com a sociedade civil pelo Fórum Municipal de Economia Solidária (FESOL-TGA) e pelo Fórum Estadual de Economia Solidária (FEES/MT). Os institucionais pela atuação do Estado via programas e políticas públicas. Também apareceram atores organizacionais, como é o caso do Ministério Público Estadual e o Ministério Público do Trabalho e um banco privado através do financiamento de um projeto de aquisição de equipamentos pela lógica da ação de responsabilidade social empresarial. Além de atores intermediários, no sentido de apoiar a criação e promover a incubação desse empreendimento o Programa da Incubadora de Organizações Coletivas Solidárias e Sustentáveis (IOCASS) alocado na Universidade do Estado de Mato Grosso (UNEMAT). Nesse elemento também apareceu o Núcleo de Políticas para Economia Solidária (NUPES).

\section{CONCLUSÕES}

Os estudos de inovação social no contexto brasileiro ainda são parcos em relação as Universidades Europeias, Canadenses e Norte Americanas. O presente texto foi construído a partir da experiência de incubação da UNEMAT junto à COOPERTAN visando testar os modelos e a escala na perspectiva das cinco dimensões: Transformações, Caráter Inovador, Inovação, Atores e Processo e atividades coletivas como proposto pelo Crises (TARDIFF et al., 2005). Esse modelo é baseado em 49 estudos realizados e nas diretrizes e propostas desenvolvidas pelo grupo Crises para a pesquisa acerca do tema. O presente estudo adaptou e aprimorou elementos das dimensões sociais (Quadro 2) com base no do trabalho de Franzoni et al. (2016).

Só o fato da criação da COOPERTAN pode ser considerada inovação social, pelo protagonismo dos catadores, pela proatividade dos catadores de materiais recicláveis em construir, dominar e internalizar 
valores e processos de autogestão dentro da cooperativa estudada, pela organização da sociedade e do poder público local para a implantação da coleta seletiva através do Programa Tangará Recicla.

Os resultados apontaram que na organização estudada foram identificadas as cinco dimensões: transformações, caráter inovador, inovação, atores e processo. Ainda foram acrescidas dimensões para atender ao peculiar caso estudado. Não chega ser uma contribuição teórica, mas pode contribuir para abrir uma lacuna de pesquisa, se o estudo incluir a análise de um grupo de cooperativas de catadores. Esse contexto brasileiro se mostrou rico para a análise, mostrando que a metodologia proposta por Tardif et al. (2005) e adaptado por Franzoni et al. (2016) é perfeitamente aplicável para analisar casos de inovações em cooperativas de catadores de materiais recicláveis.

\section{REFERÊNCIAS}

AGOSTINI, M. R.; VIEIRA, L; BOSSLE, M. B.. Social innovation as a process to overcome institutional voids: a multidimensional overview. Revista de Administração Mackenzie, v.17, n.6, p.72-101, 2016.

ANDRÉ, I.; ABREU, A.. Dimensões e espaços da inovação social. Finisterra, v.41, n.81, p.121-141., 2006. DOI: https://doi.org/http://dx.doi.org/10.18055/Finis1465

BATAGLIN, J.; KRUGLIANSKAS, I.; DELATORRE, M.. Dimensões da inovação social: o caso do banco palmas. In: ENCONTRO INTERNACIONAL SOBRE GESTÃO EMPRESARIAL E MEIO AMBIENTE, 18. Anais. São Paulo: ENGEMA, 2016.

BIGNETTI, L. P.. As inovações sociais: uma incursão por ideias, tendências e focos de pesquisa. Ciências Sociais Unisinos, v.47, n.1, 2011. DOI: https://doi.org/10.4013/csu.2011.47.1.01

CLOUTIER, J.. Qu'est-ce que I'innovation sociale?. Cahier du Crises. Collction Etudes Theoriques. N et 0313. Quebec: Crises, 2003.

DELGADO, A. A. S.. Framework para caracterizar la innovación social sobre sus procesos. 2016.

FARFUS, D.; ROCHA, M. C. S.. Inovações Sociais Volume II. 2 ed. Dados, 2007.

FERREIRA, L. B.; TORRECILHA, N.; MACHADO, S. H. S.. A técnica de observação em pesquisa de Administração.. In: ENCONTRO DA ANPAD. Anais. 2012. p.1-15.

FRANZONI, G. B.; SILVA, T. N.. Inovação Social e Tecnologia Social: o caso da Cadeia Curta de Agricultores Familiares e a Alimentação Escolar em Porto Alegre/RS. Desenvolvimento em Questão, v.14, n.37, p.353-386. 2016. DOI: https://doi.org/10.21527/2237-6453.2016.37.353-386

GIL, A. C.; LICHT, R. H. G.; OLIVA, E. C.. Case study method in business administration research. Revista de Administração e Contabilidade da Unisinos, v.2, n.1, p.47-56, 2005.

GUTIÉRREZ, A. C. M.. Innovación social: un ámbito de interés para los servicios sociales. Zerbitzuan: Gizarte zerbitzuetarako aldizkaria= Revista de servicios sociales, n.45, p.151-175, 2009.
JOÃO, I. S.. Modelo de gestão da inovação social para empresas sociais. Tese (Doutorado em Ciencias) Universidade de São Paulo, São Paulo, 2014.

LE BER, M. J.; BRANZEI, O.. forming strategic cross-sector partnerships: Relational processes of social innovation. Business \& Society, v.49, n.1, p.140-172, 2010. DOI: https://doi.org/10.1177/0007650309345457

MAÇANEIRO, M. B.; CUNHA, S. K.. Eco-Inovação: um quadro de referências para pesquisas futuras. In: SIMPÓSIO DE GESTÃO DA INOVAÇÃO TECNOLÓGICA, 26. Anais. Brasília: ANPAD, 2010.

MOORE, M; WESTLEY, F.. Surmountable chasms: networks and social innovation for resilient systems. Ecology and society, Nova Escócia, v.16, n.1, 2011.

MOULAERT, F.; MARTNELLI, F.; GONZALES, S.. Introduction: social innovation and governance in European cities: urban development between path dependency and radical innovation. journals.sagepub.com, v.14, n.3, p.195-209, 2007. DOI: https://doi.org/10.1177/0969776407077737

MURRAY, R.; CAULIER-GRICE, J.; MULGAN, G.. The open book of social innovation. London: National endowment for science, technology and the art, 2010.

NEUMEIER, S.. Why do social innovations in rural development matter and should they be considered more seriously in rural development research?-Proposal for a stronger focus on social innovations in rural development research. Sociologia ruralis, v.52, n.1, p.48-69, 2012.

NOVY, A.; LEUBOLT, B.. Participatory budgeting in Porto Alegre: social innovation and the dialectical relationship of state and civil society. Urban studies, v.42, n.11, p.20232036, 2005.

OLIVEIRA, N. D. A.; SILVA, T. N.. Inovação social e tecnologias sociais sustentáveis em relacionamentos intercooperativos: um estudo exploratório no CREDITAG-RO. Revista de Administração Da UFSM, v.5, n.2, p.277-295, 2012. DOI: https://doi.org/10.5902/198346595655

PATIAS, T. Z.; MAFFINI, J. M. O.; BOBSIN, D.; LISZBINKI, B. B. Modelos de análise da inovação social: o que temos até agora?. Revista Brasileira de Gestão e Inovação, v.4, n.2, 
p.125-147, 2017. DOI:

https://doi.org/10.18226/23190639.v4n2.07

PHILLIPS, W.; LEE, H.; GHOBADIAN, A.; O'REGAN, N.; JAMES,

P.. Social Innovation and Social Entrepreneurship: A

Systematic Review. Group \& Organization Management,

v.40, n.3, p.428-461, 2015. DOI:

https://doi.org/10.1177/1059601114560063

QUIRINO, B. S.; ALVARENGA NETO, R. C. D.; CARVALHO, R. B.; GOULART, I. B.. Análise do programa habitacional Minha Casa, Minha Vida nas perspectivas da inovação social e a evolução das políticas públicas. Revista de Gestao Social e Ambiental, v.9, n.3, p.97-117, 2015. DOI:

https://doi.org/10.5773/rgsa.v9i3.1031

SILVA, P. M. L.; SANTOS, V. F.. Inovação Social em Cooperativa de Empreendimentos Solidários. Revista de
Administração de Roraima - RARR, v.6, n.3, p.698, 2016.

DOI: https://doi.org/10.18227/2237-8057rarr.v6i3.4060

TARDIF, C.; HARRISSON, D.. Complémentarité, convergence et transversalité: la conceptualisation de l'innovation sociale au CRISES. S. Retrieved from, 2005.

TAYLOR, J. B.. Introducing social innovation. The Journal of Applied Behavioral Science, v.6, n.1, p.69-77, 1970.

TIDD, J.; BESSANT, J.. Gestão da inovação-5. Porto Alegre: Bookman, 2015.

TRIPP, D.. Pesquisa-ação: uma introdução metodológica. Educação E Pesquisa, v.31, n.3, p.443-466, 2005. DOI: https://doi.org/10.1590/S1517-97022005000300009

A CBPC - Companhia Brasileira de Produção Científica (CNPJ: 11.221.422/0001-03) detém os direitos materiais desta publicação. Os direitos referem-se à publicação do trabalho em qualquer parte do mundo, incluindo os direitos às renovações, expansões e disseminações da contribuição, bem como outros direitos subsidiários. Todos os trabalhos publicados eletronicamente poderão posteriormente ser publicados em coletâneas impressas sob coordenação da Sustenere Publishing, da Companhia Brasileira de Produção Científica e seus parceiros autorizados. Os (as) autores (as) preservam os direitos autorais, mas não têm permissão para a publicação da contribuição em outro meio, impresso ou digital, em português ou em tradução. 